\title{
Influence of Air Movement Preference on Thermal Comfort in Naturally Ventilated Classrooms of India
}

\author{
Nagaraju Kaja* and Dr. Ramesh Srikonda \\ Department of Architecture, School of Planning and Architecture, Vijayawada 520008, India; \\ nagaraju.kaja@spav.ac.in, ramesh.srikonda@spav.ac.in
}

\begin{abstract}
Background and objectives: Thermal comfort is very essential for a comfortable stay in any indoor space. Comfort conditions of indoor spaces are influenced by parameters like air movement, humidity, air temperature, etc. The aim of this research is to assess the air movement preferences by the occupants in classrooms of the selected higher education institutes in hot humid climate of India. Methods/statistical analysis: Surveys were conducted in all the three seasons of the year as per ASHRAE standard procedures. Environmental variables were measured in classrooms while questionnaires were distributed to the occupants simultaneously. A total of 361 students were surveyed with 1444 data sets for the whole year. Findings: Outdoor ( $T_{\text {out }}$ ) temperatures were recorded and regression analysis has been done to find the relationship between the mean outdoor temperatures with the indoor operative temperatures $\left(T_{\mathrm{op}}\right)$ recorded. The acceptance of air movement in classrooms during summer is $10-15.4 \%$, in moderate season it is $5.6-30 \%$ and during winter it is up to $58 \%$. Improvements/application: This study enables to understand the influence of air movement preference on occupant's thermal comfort in classrooms of hot and humid climate of India. This will help in creating a comfortable environment in classrooms of higher education through placement and designing of openings for increased air movement thereby improving the thermal comfort conditions. This research assessed the movement of air in the classrooms of higher education and the occupants air movement preference for thermal comfort. This study is a starting point for the adaptive thermal comfort research in hot and humid climate of Vijayawada region.
\end{abstract}

Keywords: Thermal Comfort, Air Movement Preference, Naturally Ventilated Classrooms, Environmental Factors

\section{Introduction}

Buildings are designed for human activity and are as per user's requirements, needs, and aspirations. A good thermal environment is essential for human wellness and comfort. 1 Increasingly, more building research has been done considering people's participation, behaviour adjustment, and their subjective psychological specifics. ${ }^{2}$ The condition of the mind that expresses satisfaction with the thermal environment. $\underline{3}$ A happy thermal environment around keeps people healthy both physically and psychologically. Comfortable environment is a situation where an individual shall not feel too cold or hot in the surrounding thermal environment having adequate air movement and lighting. $\underline{4}$ Subjective parameters like climate, age, sex, health and objective parameters like air temperature and speed, relative humidity, radiant temperature of the bodies which are in proximity shall also impact the thermal comfort. $\frac{5}{}$ Researchers like Mendell and Heath, Wyon proved through research that the higher air temperatures in the learning atmosphere can impact the performance of the occupant's negatively. 6.7 Same time low ventilation rates can cause respiratory symptoms and reducing concentration levels in indoors. $\underline{8}$ The interactions between occupant and immediate environment in a naturally ventilated building are much more dynamic and the occupant's behavioural, physiological, and psychological adaptations are wider compared to conditioned buildings ${ }^{9}$ Air movement is one of the most important environmental variables which can impact the thermal comfort conditions in a space. $\underline{10}-\underline{17}$

${ }^{*}$ Author for correspondence 
Naturally ventilated buildings can provide comfortable living in all the seasons yet still uses less energy when compared to air-conditioned buildings. $\underline{18,19}$ Indian building stock consists of naturally ventilated buildings or partially air-conditioned buildings mostly. From time, immemorial, naturally ventilated buildings are considered comfortable by common people in India. But designing naturally ventilated buildings with good thermal conditions is all the more difficult task than similar but air-conditioned building owing to stringent requirement of meeting thermal comfort for minimum of $80 \%$ of occupants for $90 \%$ of occupied hours and narrow thermal comfort band as per the international standards ASHRAE 55. $\underline{20}$ Design and use of naturally ventilated buildings, if propagated can provide comfortable thermal environment for better occupant wellbeing and also for reduced carbon footprint. But in the context of no available comfort standards for buildings in India, people are adopting to easy solution of converting the spaces to conditioning increasing the energy consumption and carbon footprint. As per the standards ASHRAE, $\underline{21}$ the permissible air speed for warm climate is $0.2-1.50 \mathrm{~m} / \mathrm{s}$ and this air velocity range do not unequivocally address the acceptability of air movement, but focuses mainly on the thermal comfort conditions of the space as a whole. Heat tolerance levels of students are higher and there are no specific standards for classrooms in India. $\underline{22}$ Recently, it has widely seen that people are using air conditioning systems widely, increasing energy consumption and thereby carbon footprint. The results of thermal comfort studies help in the formulation of thermal comfort standards enhancing the existing Indian building $\operatorname{codes} \underline{23}$ as shown in Figure 1.
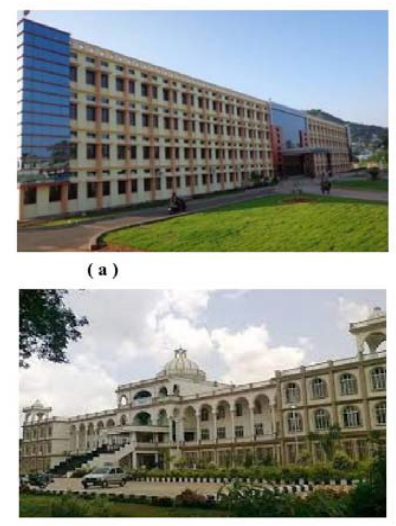

(c)

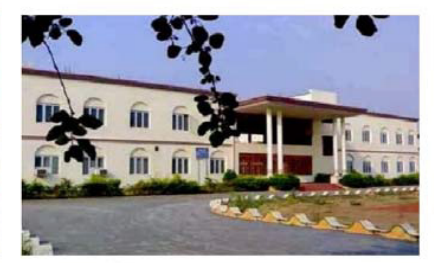

(b)

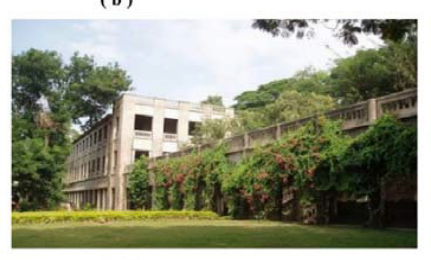

(d)
Figure 1. Investigated institute buildings (a) ALIET (b) SIHM\&CT (c) VSRCE, and (d) ALC-PG (Source: author).

\section{Environmental Factors Affecting Thermal Comfort}

As listed by $\underline{24}$ in his research works, the below environmental variables influence thermal comfort:

\subsection{Air Temperature}

It is the temperature of the air surrounding a body. ${ }^{4}$ It is usually given in degrees Celsius $\left({ }^{\circ} \mathrm{C}\right)$. It is an important environmental variable which affects thermal comfort. Air freshness and suitable temperature are the most important variables required for built environment. $\underline{25}$

\subsection{Radiant Temperature}

The temperature around an occupant, including the thermal radiation emitted from any equipment, sky and surrounding surfaces around it. Mean radiant temperature (MRT) is measured by globe thermometer. MRT may be calculated by using air temperature $\left(T_{\mathrm{a}}\right)$ with the following equation: $\mathrm{MRT}=0.99 \mathrm{~T}_{\mathrm{a}}-0.01\left(\mathrm{R}^{2}=0.99\right) . \underline{\underline{26}}$

\subsection{Air Velocity}

An average of the instantaneous air velocity over an interval of time. $\underline{2}$ It is the speed of air moving across the occupants of an area and may help cool them if the air is cooler than the environment. Air velocity is an important factor influencing the thermal comfort. More the air, the occupants may feel comfortable.

\subsection{Relative Humidity}

As per ASHRAE, it is "the ratio of the partial pressure (or density) of the water vapor in the air to the saturation pressure (or density) of water vapor at the same temperature and the same total pressure." $=$ Other than the environmental factors, personal factors like clothing insulation, metabolic rate will also influence the thermal comfort of a space.

\subsection{Operative Temperature $\left(T_{\mathrm{op}}\right)$}

Operative temperature is an important factor influencing thermal comfort which is used by researchers in their researches. Operative temperature combines the impact of both air temperature and radiant temperature without air movement and relative humidity. The operative temperature can be considered by taking the average 
of air temperature and mean radiant temperature if the occupants' metabolic rates are between 1.0 and 1.3 met, no direct sunlight into the space, average air velocity less than $0.2 \mathrm{~m} / \mathrm{s}$ and the difference of average air temperature and MRT is not more than $4^{\circ} \mathrm{C} ., \underline{4}, \underline{27}$ As per ASHRAE, 2013, average of air temperature may be considered as operative temperature when there are no radiant heating systems in the space and the weighted average $U$ value of the external wall or window $\left(U_{w}\right)$, satisfies the equation

$\mathrm{U}_{\mathrm{w}}<50\left(\mathrm{t}_{\mathrm{d}} \mathrm{I}-\mathrm{t}_{\mathrm{d}}, \mathrm{e}\right)$, where $\mathrm{U}_{\mathrm{w}}=$ weighted average $\mathrm{U}$ value of the external wall or window $\left(\mathrm{W} / \mathrm{m}^{2} \mathrm{~K}\right)$,

$\mathrm{t}_{\mathrm{d},} \mathrm{i}=$ internal design temperature in ${ }^{\circ} \mathrm{C}$

$\mathrm{t}_{\mathrm{d}} \mathrm{e}=$ external design temperature in ${ }^{\circ} \mathrm{C}$ and SHGC of window glass is not more than 0.48 .

\section{Methodology}

Data were collected in the surveyed classrooms by using Testo 480 of size of $81 \mathrm{~mm} \times 235 \mathrm{~mm} \times 39 \mathrm{~mm}, 1.8$ GB internal memory with humidity probe and a globe thermometer constructed by the researcher using a 110 $\mathrm{mm}$ plastic ball painted with matt black and by inserting mercury in glass thermometer inside. The equipment used for the survey is presented in Figure 2 and the ranges and other technical detail of the instrument below is described in Table 1. Air velocity, air temperature, and relative humidity were recorded by placing the instrument at a height of $1.1 \mathrm{~m}$ from the finished floor level. A questionnaire based on ASHRAE $55^{3}$ adaptive comfort guidelines was used to get the responses from the students in each class.

\subsection{Climate}

Vijayawada is located on the banks of river Krishna in the state of Andhra Pradesh in southern part of India. The new capital of Andhra Pradesh "Amaravathi" is

Table 1. Different parameters of the instrument

\begin{tabular}{|l|l|l|l|l|}
\hline $\begin{array}{l}\text { S. } \\
\text { no }\end{array}$ & Parameter & Temp & Humidity & Velocity \\
\hline 1 & $\begin{array}{l}\text { Measurement } \\
\text { range }\end{array}$ & $\begin{array}{l}-100 \text { to } \\
+400^{\circ} \mathrm{C}\end{array}$ & $\begin{array}{l}0 \text { to } 100 \% \\
\mathrm{RH}\end{array}$ & $\begin{array}{l}0 \text { to }+20 \\
\mathrm{~m} / \mathrm{s}\end{array}$ \\
\hline 2 & Accuracy & $\begin{array}{l} \pm\left(0.5^{\circ} \mathrm{F}+\right. \\
0.1 \% \text { of } \mathrm{mv})\end{array}$ & & \\
\hline 3 & Resolution & $\begin{array}{l}0.01^{\circ} \mathrm{F} / 0.01 \\
{ }^{\circ} \mathrm{C}\end{array}$ & $0.1 \% \mathrm{RH}$ & $\begin{array}{l}1.97 \\
\mathrm{fpm} / 0.01 \\
\mathrm{~m} / \mathrm{s}\end{array}$ \\
\hline
\end{tabular}
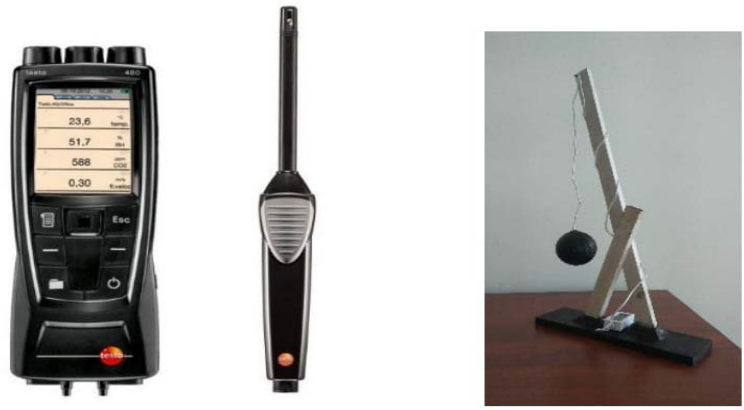

Testo 480 \& Temp with Humidity Probe \& Globe thermometer

Figure 2. Instruments used for the survey.

located $30 \mathrm{~km}$ from Vijayawada. It is located at $16.5193^{\circ} \mathrm{N}$ $80.6305^{\circ} \mathrm{E}$ and has an altitude of $11 \mathrm{~m}$ (36 ft.). The climate of Vijayawada city is warm-humid with hotter summer seasons and monsoons with a higher percentage of humidity. Temperatures can go up to $48{ }^{\circ} \mathrm{C}\left(118{ }^{\circ} \mathrm{F}\right)$ during May-June and winter temperatures from 18.8 to $25^{\circ} \mathrm{C}$. The average humidity is $78 \%$, and it will cross $80 \%$ during moderate (monsoon) seasons. The average annual rainfall is 977.9 millimetres (36 inches) and Southwest and Northeast monsoon gets the rainfall. Climate data ${ }^{28}$ of Vijayawada are presented in Table 2.

Table 2. Climate data of study area (Vijayawada)

\begin{tabular}{|l|l|l|l|l|l|l|}
\hline \multirow{2}{*}{ Month } & \multicolumn{3}{|l|}{ Temperature in ${ }^{\circ} \mathrm{C}$} & $\begin{array}{l}\mathbf{R H} \\
(\%)\end{array}$ & $\begin{array}{l}\text { Air } \\
\text { velocity } \\
\text { in m/s }\end{array}$ & $\begin{array}{l}\text { Precipitation } \\
\text { in } \mathbf{~ m m ~}\end{array}$ \\
\cline { 2 - 7 } & Min & Max & Average & \\
\hline January & 18.9 & 30.1 & 24.5 & 76 & 1.39 & 1 \\
\hline February & 20.1 & 32.8 & 26.4 & 76 & 1.67 & 4 \\
\hline March & 22.6 & 35.4 & 29 & 75 & 1.94 & 5 \\
\hline April & 25.8 & 37.5 & 31.6 & 73 & 2.5 & 15 \\
\hline May & 27.9 & 39.6 & 33.7 & 67 & 2.78 & 71 \\
\hline June & 27.4 & 37.5 & 32.4 & 67 & 2.78 & 136 \\
\hline July & 25.4 & 32.9 & 29.1 & 74 & 2.5 & 250 \\
\hline August & 25.2 & 32.4 & 28.8 & 77 & 2.22 & 197 \\
\hline September & 25.2 & 32.6 & 28.9 & 79 & 1.67 & 164 \\
\hline October & 24.2 & 31.8 & 28 & 81 & 1.67 & 169 \\
\hline November & 20.9 & 30.4 & 25.6 & 78 & 1.94 & 45 \\
\hline December & 18.8 & 29.5 & 24.1 & 75 & 1.67 & 10 \\
\hline
\end{tabular}

Climate data table made based on the data accessed at http://www.Climate-data. org/asia/india/andhra-pradesh/vijayawada-715084/\#temperature-graph, Data accessed: 30/09/19. 


\subsection{Case Study Areas}

The classrooms of four higher education institutes were selected from the city and surroundings were representing the wider cross-section of the graduate students studying in these institutions of the region. The field studies include subjective surveys of the occupants and recording the physical measurements and the environmental variables like air temperature and humidity, etc. in the classrooms. The surveys were conducted for the period of a year during 2017-18.

The Andhra Loyola institute of Engineering and Technology (ALIET) is an old institution offering various courses at Bachelors and master's level in Engineering. Siddhartha Institute of Hotel Management and catering Technology (SIHM\&CT) offers courses in hotel Management and situated as part of a 33-acre campus in a prime locality of Vijayawada. College of Architecture and Planning (ANU CAP) is located inside the Acharya Nagarjuna University campus and $25 \mathrm{~km}$ from Vijayawada on National highway. Andhra Loyola college for Post Graduate studies (ALC-PG) is a part of Andhra Loyola Campus which is one of the premier institutions in Vijayawada and runs various departments with at UG and PG level.

\subsection{Data Collection}

\subsubsection{Physical Measurements of the Study Areas}

Case study surveys were conducted by taking physical measurements in the classrooms of the selected institutions and the perceptions of the occupants through questionnaire survey. Both the surveys were conducted simultaneously during the field visits. The floor plans of the surveyed classrooms are presented in Figure 3.

Measured environmental variables of all the case studies are presented in Table 3 . The mean air velocity across all the study areas during summer is $0.31 \mathrm{~m} / \mathrm{s}$, for moderate season it is 0.18 and during winter it is 0.23 $\mathrm{m} / \mathrm{s}$. The mean outdoor temperatures recorded during the surveys are $32.9{ }^{\circ} \mathrm{C}$ during summer, $28.9^{\circ} \mathrm{C}$ during moderate season, and $26.1{ }^{\circ} \mathrm{C}$ during winter. Recorded mean relative humidity ( $\mathrm{RH}$ ) in the classrooms are $56 \%$ during summer, $58.6 \%$ during moderate season, and $63.9 \%$ during winter.

\subsubsection{Subjective Survey of the Occupants}

A questionnaire was prepared as per ASHRAE 55 standard ${ }^{28}$ and issued to students for giving their input

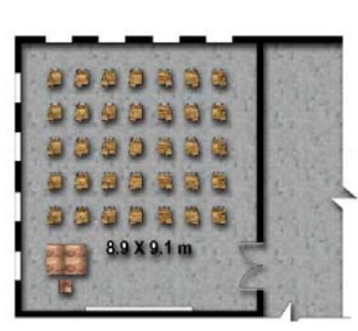

(a)

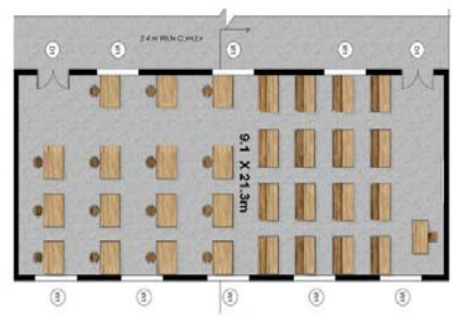

(c)

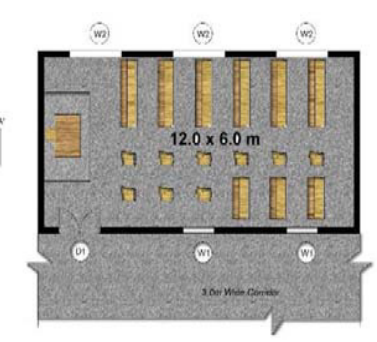

(b)

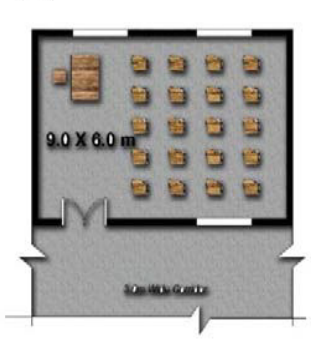

(d)
Figure 3. Acceptability of air movement in classrooms of study areas on ASHRAE scale.

Table 3. Measured environmntal variables of the study areas

\begin{tabular}{|l|l|l|l|l|l|l|}
\hline \multirow{4}{*}{ Season } & Institute & $\boldsymbol{T}_{\text {op }}$ & $\mathbf{R H}$ & $\begin{array}{l}\text { Air } \\
\text { speed }\end{array}$ & $\boldsymbol{T}_{\text {a }}$ & $\boldsymbol{T}_{\text {out }}$ \\
\hline \multirow{5}{*}{ Summer } & ANU CAP & 33.4 & 56.4 & 0.32 & 32.3 & 33.9 \\
\cline { 2 - 7 } & ALIET & 33.5 & 61.3 & 0.48 & 32.5 & 33.3 \\
\cline { 2 - 7 } & MSPA & 34.4 & 55.6 & 0.14 & 34 & 32.2 \\
\cline { 2 - 7 } & ALC-PG & 35 & 51.2 & 0.18 & 34.3 & 35.2 \\
\cline { 2 - 7 } & SIHM\&CT & 34.3 & 55.5 & 0.42 & 33.2 & 30 \\
\hline \multirow{5}{*}{ Moderate } & ANU CAP & 31.2 & 57 & 0.24 & 30.8 & 28.3 \\
\cline { 2 - 7 } & ALIET & 30.8 & 54 & 0.21 & 30.5 & 31.2 \\
\cline { 2 - 7 } & MSPA & 31.75 & 71.3 & 0.11 & 31 & 27.8 \\
\cline { 2 - 7 } & ALC-PG & 30.42 & 55 & 0.18 & 30.2 & 28.3 \\
\cline { 2 - 7 } & SIHM\&CT & 30.7 & 55.9 & 0.15 & 29.8 & 28.9 \\
\hline \multirow{5}{*}{ Winter } & ANU CAP & 27.12 & 61 & 0.28 & 26.8 & 24.4 \\
\cline { 2 - 7 } & ALIET & 26.56 & 63.5 & 0.19 & 26.2 & 30.1 \\
\cline { 2 - 7 } & MSPA & 26.95 & 68 & 0.28 & 25.3 & 23.9 \\
\cline { 2 - 7 } & ALC-PG & 28.45 & 65 & 0.22 & 28.3 & 25.6 \\
\cline { 2 - 7 } & SIHM\&CT & 27.6 & 62 & 0.2 & 28.3 & 26.7 \\
\hline
\end{tabular}

about the questions which is divided in two sections (i) Personal information like gender, age, height and weight, etc and (ii) Questions about occupants' perceptions about the indoor environment. Subjects are all of the graduate 
students in the age group of 20-24 old and the metabolic value is considered as 1.2 since all the occupants are engaged in sedentary activities like writing, listening, etc. in the classrooms. Surveys were conducted four times in a day between 9 AM and 5 PM during the field visits. In total, 1444 questionnaires were collected from 361 students through the surveys conducted in summer, moderate season, and winter across the classrooms of selected institutes of higher learning. Questions were asked on a seven-point scale about the acceptance of air movement in classrooms described as "unacceptable", "moderately unacceptable", "slightly unacceptable", "slightly acceptable", "moderately acceptable", and "acceptable". Preference of air movement was asked on a three-point scale as described as "more", "less", and "no change". Subjective questionnaires were distributed to the participants well before the start of the survey and occupants were explained about the purpose and objectives of the research study.

\section{Results and Discussion}

Surveys conducted for a year during summer, moderate season, and winter during 2017-18 and the results are presented in Figures 4 and 5. Figure 4 presents the percentage of the acceptability of the occupants about the environmental conditions in the classroom on a five-point scale, and Figure 5 presents the percentage of occupants' preference about the prevailing air movement in the classrooms.

During summer in ANU CAP, 27.6\% not accepted the air movement and $10.4 \%$ only accepted it. In ALC

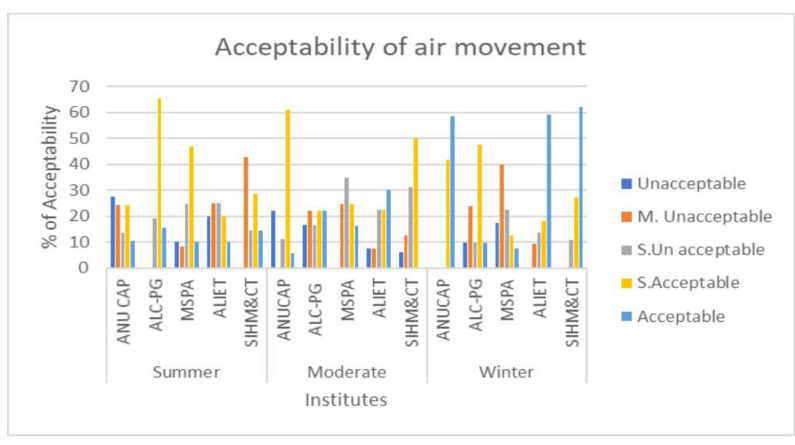

$\%$ of occupant's acceptability of Air movement in class rooms of surveyed Institutional Buildings

Figure 4. Acceptability of air movement in classrooms of study areas on ASHRAE scale.

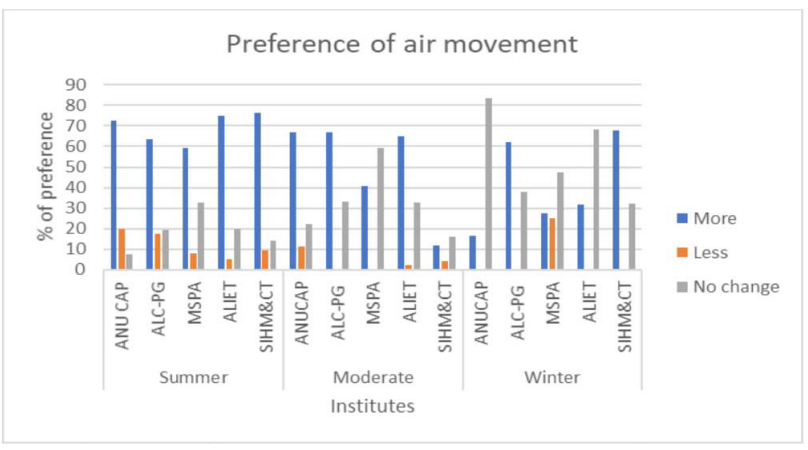

$\%$ of occupant's preference of Air movement in classrooms of surveyed Institutional Buildings

Figure 5. Preference of air movement in classrooms of study areas on ASHRAE scale.

PG, $15.4 \%$ accepted it and $65.4 \%$ slightly accepted it. In MSPA, 10.2\% not accepted and 10.2\% accepted the air movement. In ALIET, acceptance of air movement is $10 \%$ and $20 \%$ of the occupants have not accepted the same. In SIHM\&CT, acceptance of air movement is $14.3 \%$ and $42.8 \%$ of the occupants mostly unaccepted the air movement in the classroom. During moderate season, in ANU CAP, acceptance of air movement is 5.6\% and 22.2\% of the occupants have not accepted it. In ALC PG, 16.7\% not accepted it and 22.2\% accepted it. In MSPA, 16.3\% of occupants accepted air movement. In ALIET, 30\% accepted it and $7.5 \%$ not accepted the air movement. In SIHM\&CT, $50.0 \%$ of the occupants slightly accepted the air movement and 6.2\% not accepted it in the classroom. During winter months in ANU CAP, acceptance of air movement is $58.3 \%$. In ALC PG, acceptance of air movement is $9.6 \%$ and $9.5 \%$ not accepted it. In MSPA, acceptance of air movement is $7.5 \%$ and $17.5 \%$ of the occupants have not accepted it. In ALIET, acceptance of air movement is $59 \%$ and in SIHM\&CT it is $62.2 \%$. During the survey, it was observed that even though the mean air velocity is $0.31 \mathrm{~m} / \mathrm{s}$ during summer, mean of percentage of not accepting the air movement is $37.8 \%$ across all the institutes. We can understand with this that students were voting based on their perceptions than the actual physical measurement of the air velocity. In Figure 4, in ANU CAP, during summer $72.4 \%$ of the occupants preferred more air movement, in moderate season, $66.7 \%$ and during winter it is $16.7 \%$. In ALC-PG, during summer $63.5 \%$ of the occupants preferred more air movement, in moderate season, $66.7 \%$ and during winter it is $61.9 \%$. In MSPA, during summer $59.2 \%$ of 
the occupants preferred more air movement, in moderate season, $40.8 \%$ and during winter it is $27.5 \%$. In ALIET, during summer $75 \%$ of the occupants preferred more air movement, in moderate season, $65 \%$ and during winter it is $31.8 \%$. In SIHM\&CT, during summer $76.2 \%$ of the occupants preferred more air movement, in moderate season, $12 \%$ and during winter it is $67.6 \%$.

\subsection{Relation Between Recorded Operative Temperatures $\left(T_{\mathrm{op}}\right)$ and Thermal Sensation of the Occupants (tsv)}

Indoor operative temperatures were recorded during the field studies in all the study areas. The cross-tabulation of indoor operative temperature $\left(T_{\mathrm{op}}\right)$ and thermal sensation votes (tsv) obtained through questionnaire are presented in Table 4.

To calculate the relation between the measured thermal sensation of the occupants and the recorded indoor operative temperatures $\left(T_{\mathrm{op}}\right)$, linear regression analysis has been done. The results of the regression analysis are presented in Figure 6. Through the regression analysis between thermal sensation of the occupants and the recorded indoor operative temperatures, the correlation found is tsv $=0.2913 T_{\text {op }}-8.6257$ (correlation coefficient $\left.\mathbf{R}^{2}=0.3332, \mathrm{p}<0.01\right)$

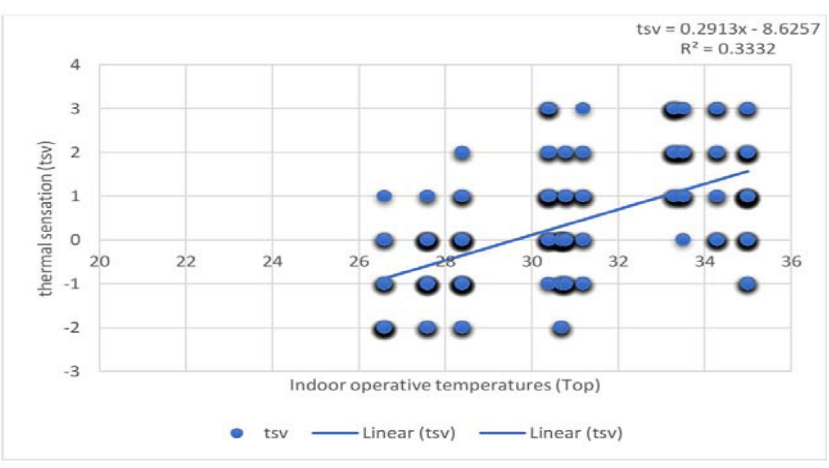

Regression analysis between recorded thermal sensation of occupants and operative temperatures recorded $\left(T_{\mathrm{op}}\right)$ of classrooms

Figure 6. Regression between thermal sensation of occupants and top of classrooms.

It shows that there is a correlation exists between the indoor operative temperature and thermal sensation of the occupants in the studied population.

\subsection{Relation Between Air Movement Preference and Thermal Comfort}

From the analysis presented in Figure 7, it is observed that $100 \%$ of the occupants who have voted thermal sensation as hot $(+3), 98 \%$ of the occupants who voted for

Table 4. Cross-tabulation of indoor operative temperature (Top) and thermal sensation votes (tsv)

\begin{tabular}{|c|c|c|c|c|c|c|c|c|}
\hline Institute & $T_{\mathrm{op}}$ & Cold & Cool & Slightly cool & Neutral & Slightly warm & Warm & Hot \\
\hline \multicolumn{9}{|l|}{ Summer } \\
\hline ANU CAP & 33.36 & 0 & 0 & 0 & 0 & 24.1 & 34.5 & 41.4 \\
\hline ALC-PG & 35 & 0 & 0 & 9.6 & 15.4 & 42.3 & 25 & 7.7 \\
\hline ALIET & 33.54 & 0 & 0 & 0 & 5 & 40 & 40 & 15 \\
\hline SIHM\&CT & 34.31 & 0 & 0 & 0 & 38 & 14.4 & 23.8 & 23.8 \\
\hline SPAV & 31.5 & 0 & 0 & 0 & 16.4 & 23.3 & 23.3 & 37 \\
\hline \multicolumn{9}{|c|}{ Moderate season } \\
\hline ANUCAP & 31.2 & 0 & 0 & 22.2 & 22.2 & 33.3 & 16.7 & 5.6 \\
\hline ALC-PG & 30.42 & 0 & 0 & 27.8 & 27.8 & 16.7 & 11 & 16.7 \\
\hline ALIET & 30.8 & 0 & 0 & 28.6 & 32.1 & 25 & 14.3 & 0 \\
\hline SIHM\&CT & 30.7 & 0 & 0 & 25 & 62.5 & 12.5 & 0 & 0 \\
\hline VRSEC & 30.6 & 0 & 12.5 & 12.5 & 50 & 25 & 0 & 0 \\
\hline \multicolumn{9}{|l|}{ Winter } \\
\hline ANUCAP & 28.12 & 0 & 20.8 & 41.7 & 37.5 & 0 & 0 & 0 \\
\hline ALC-PG & 28.45 & 0 & 0 & 14.3 & 47.6 & 23.8 & 10.5 & 0 \\
\hline ALIET & 26.56 & 0 & 50 & 27.3 & 18.2 & 4.5 & 0 & 0 \\
\hline SIHM\&CT & 27.6 & 0 & 13.5 & 40.5 & 40.5 & 5.5 & 0 & 0 \\
\hline
\end{tabular}


warm (+2), and $73.3 \%$ of the occupants voted for slightly warm $(+1)$ also preferred for more air movement in the classroom. The percentage of the occupants preferred for more air movement has gradually reduced towards cooler sensation from hot sensation. $54.5 \%$ of the occupants voted for neutral (0) on thermal sensation also voted for more air movement and $42.7 \%$ voted for no change in the air movement. $36 \%$ of the occupants voted for slightly cool $(-1)$ on thermal sensation also preferred for more air movement and $46.7 \%$ voted for slightly cool $(-1)$ preferred no change in air movement. $20.7 \%$ of the occupants voted for cool $(-2)$ on thermal sensation also voted for more air movement and $68.9 \%$ voted for cool $(-2)$ preferred for no change in air movement where as $10.3 \%$ voted for voted for cool $(-2)$ also preferred for less air movement in the room.

In Figure 8, it is interpreted that $48.2 \%$ of the occupants who voted as accepted the thermal environment indoors also preferred for more air movement, $44.5 \%$ preferred no change in the air movement. $67 \%$ of the occupants wanted more air movement and preferred that the thermal environment in classroom not acceptable.

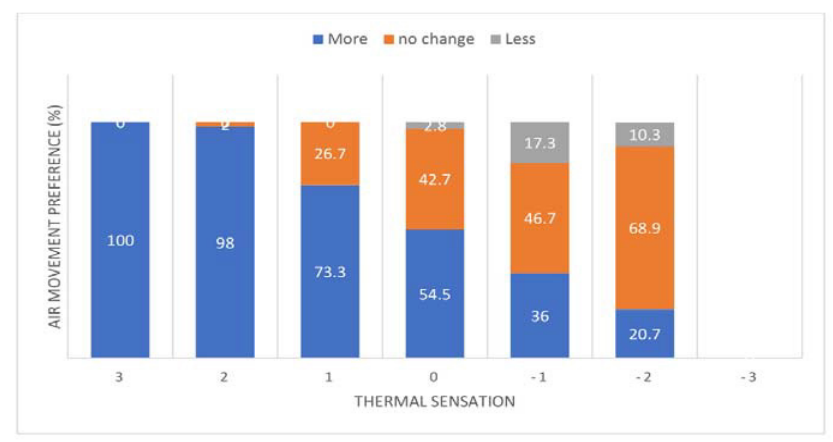

Figure 7. Distribution of air movement preference votes on thermal sensation scale.

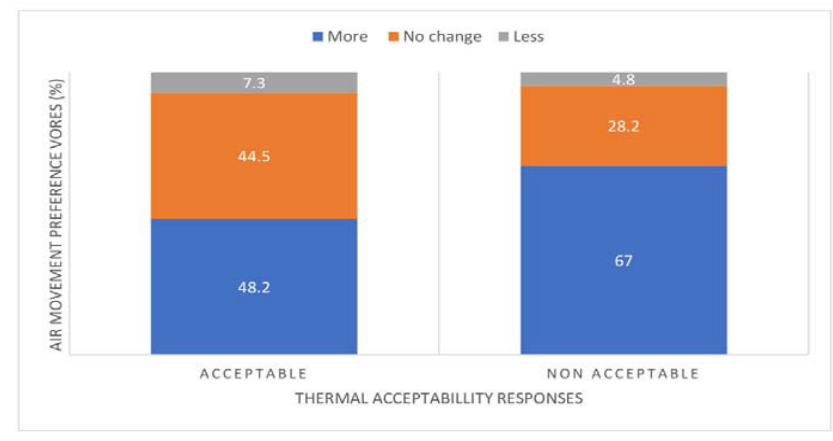

Figure 8. Distribution of air movement preference votes on thermal acceptability.
Interestingly, $28.2 \%$ of them preferred for no change in the air movement.

\section{Conclusions}

Subjective and objective surveys were conducted in the classrooms of the selected institutes of higher education in hot and humid climate of India to understand the air movement preferences of the occupants and the impact of air movement on the thermal comfort. The important findings are presented below:

- In the classrooms where research surveys were conducted, most of the occupants are not satisfied with the air movement in their classrooms in all the three seasons.

- The acceptance of air movement during winter season is good with $58 \%$ of acceptance and much lower in summer season with less than $16 \%$ acceptability.

- The air movement preference is not uniform in all the surveyed classrooms and this may be due to the location of the classrooms, placement of openings and its surroundings like trees, open areas, etc.

- Most of the occupants preferred more air movement in the classrooms than the prevailing conditions. Nearly $50 \%$ of the occupants who have accepted the thermal environment in classrooms have preferred for more air movement. Percentage of occupant's preferring for more air movement is $63.5-76.2 \%$ during summer, $12-66.7 \%$ during moderate season, and $16.7-67.6 \%$ during winter.

- It proves that the students in naturally ventilated classrooms of higher education in India are expecting more air movement than the prevailing conditions.

- It is important to note that this study provides a better understanding of the occupant behaviour in naturally ventilated classrooms. This will be useful in creating comfortable thermal conditions in naturally ventilated classrooms of higher education.

\section{Limitations}

The study is limited to assess the air movement preference and thermal comfort of the occupants. This study is focused on only on the impact of air movement preference and thermal comfort. The rest of the environmental variables and data from other questions are analysed separately. 


\section{References}

1. Jamaludin N. Indoor Thermal environment in tropical climate residential building. In: Web of conferences, EDP sciences; 2014. P. 1-6.

2. Wang $X$. An investigation of the adaptive thermal comfort research for residential buildings in China 'Hot summer and cold winter' zone. The University of Sheffield; 2013. P. 282.

3. ANSI/ ASHRAE. Thermal environmental conditions for human occupancy. [cited 2019 Oct 05]. https://en.wikipedia. org/wiki/ASHRAE_55.

4. Modeste KN. Thermal comfort and air movement preference in some classrooms in Cameroun. Revue des Energies Renouvelables. 2014;17(2):263-78.

5. Mendell MJ, Heath GA. Do indoor pollutants and thermal conditions in schools' influence student performance? A critical review of the literature, Indoor Air. 2005;15(1):27-52.

6. David WP. The effect of moderate heat stress on mental performance. Scand J Work Environ Health. 1979;5(4): 352-61.

7. Sundell J, Hal Levin, Nazaroff WW, Cain WS, Fisk WJ, Grimsrud DT, et al. Ventilation rates and health: multidisciplinary review of the scientific literature, Indoor Air. 2011;21(3):191-204.

8. Singh MK, Mahapatra S, Atreya SK. Adaptive thermal comfort model for different climatic zones of North-East India. Appl Energy. 2011;88(7):2420-28.

9. de Dear RJ, Leow KG, Foo SC. Thermal comfort in the humid tropics: field, experiments in air conditioned and naturally ventilated buildings Singapore. Int J Biometeorol. 1991;34(4):259-65.

10. Kwok AG. Thermal comfort in tropical classrooms. ASHRAE Trans. 1998;104(1B):1031-47.

11. Meyer WB. Why indoor climates change: a case study. Clim Change. 2002;55(3):395-407.

12. Wong NH, Khoo SS. Thermal comfort in classrooms in tropical. Energy Build. 2003;35(4):337-51.

13. Nicol F, Humphreys MA. Adaptive thermal comfort and sustainable thermal standards for buildings. In: Proceedings of moving thermal comfort standard; 2004. P. 150-65.

14. Yamtraipat Y, Khedari J, Hirunlabh J. Thermal comfort standards for air-conditioned buildings in hot and humid Thailand considering additional factors of acclimatization and education level. Sol Energy. 2005;78(4):504-17.
15. Hwang RL, Lin TP, Kuo NJ. Field experiments on thermal comfort in campus classrooms in Taiwan. Energy Build. 2006;38(1):53-62.

16. Ogbonna AC, Harris DJ. Thermal comfort in sub-Sahara Africa: field study report in Jos-Nigeria. Appl Energy. 2008;85(1):1-11.

17. Henry F, Wong NH. Thermal comfort for naturallyventilated houses in Indonesia. Energy Build. 1997;36(7):614-26.

18. Nicol F, Humphreys MA. A stochastic approach to thermal comfort-occupant behaviour and energy use in buildings. ASHARE Trans. 2004;110(2):554-68.

19. Kleiven T. Natural ventilation in buildings, architectural concepts, consequences and possibilities [ $\mathrm{Ph} \mathrm{D}$ thesis]. Norwegian University of Science and Technology; 2003. P. $1-305$.

20. ANSI/ASHRAE standard 55-2004. Atlanta: American Society of Heating, Refrigerating and Air Conditioning Engineers Inc; 2004. P. 1-5.

21. Griffiths I. Thermal comfort studies in buildings with passive solar features. Field studies. Report to the Commission of the European Community, UK; 1990.

22. Nagano K, Mochida T. Experiments on thermal environmental design of ceiling radiant cooling for supine human subjects. Build Environ. 2004;39(3):267-27.

23. Asit KM, Ram GM. A thermal comfort field study of naturally ventilated classrooms in Kharagpur, India, Building and Environment 2015;92:396-406.

24. ANSI/ASHRAE standard 55-2010. Thermal environmental conditions for human occupancy. Atlanta, United States; 2010. P. 1-44.

25. Humphreys MA. A study of the thermal comfort of primary school children in summer. Build Environ. 1977;12(4):231-9.

26. Han J. Field study on occupants' thermal comfort and residential thermal environment in a hot-humid climate of China. Build Environ. 2007;42:4043-50.

27. Climate. [cited 2019 Sep 30]. http://www.Climate-data. org/asia/india/andhra-pradesh/vijayawada-715084/ \#temperature-graph.

28. Nicol F. Michael Humphreys, Susan Roaf, Adaptive thermal comfort, principles and practice. London and New York: Routledge, Taylor \&Francis Group; 2012. 